\title{
Toxoplasmosis in Cats and Its Zoonotic Potential in and Around Bangladesh Agricultural University Campus
}

\author{
R. P. Sah*1, Md. H. Talukder ${ }^{2}$, A.K.M. Anisur Rahman ${ }^{3}$ and Md B. Hossain ${ }^{2}$ \\ ${ }^{1}$ Agricultural Research Station, Pakhribas, Dhankuta, Nepal \\ ${ }^{2}$ Department of Parasitology, Bangladesh Agricultural University, Mymensingh, Bangladesh \\ ${ }^{3}$ Department of Medicine, Bangladesh Agricultural University, Mymensingh, Bangladesh \\ *Corresponding author: rpsnarc@yahoo.com
}

\begin{abstract}
Toxoplasmosis is a zoonotic disease, occurs in almost all warm blooded animals including human beings and is caused by a global protozoan intracellular parasite Toxoplasma gondii. It is estimated that one third of the world human population have been infected by this parasite. This protozoan causes a significant public health problem in humans and imposes considerable economic losses and damages to livestock. The final host is cat, Feliscatus, accounts for all of these significant burdens. Hence the present study was designed to determine the prevalence rate of $T$. gondii infection in cats and also to analyze the associated factors that were potential for human beings and livestock as well in the period from September 2014 to August 2016. Altogether 254 faecal samples from cat and 390 water samples were collected from Bangladesh Agricultural University (BAU) campus, farm and residential areas of BAU and were examined for presence of T. gondii oocysts at Department of Parasitology, BAU Mymensingh. The overall prevalence of $T$. gondii was $4.03 \%$ (26/644). Presence of $T$. gondii oocysts in faecal and water samples were $5.5 \%$ (14/254) and 3.08\% (12/390), respectively. Adult cats had higher (6.7\%) prevalence than young cats (3.8\%). Summer season was found high prevalence (6.7\%) of oocysts in cat faeces. Similarly drain water found higher positivity (6.67\%) of oocysts. Therefore, this study concluded that the cats are contaminating the environment by shedding oocysts and then other animals can get the infection from grazing of contaminated grasses and drinking water. So eating undercooked goat, sheep and cattle meat; eating contaminated vegetables and drinking contaminated water are major sources for getting toxoplasmosis to human beings. Hence this disease has great zoonotic importance around BAU campus and therefore it is essential to create public awareness.
\end{abstract}

Keywords: Toxoplasmosis, Cat, Zoonotic potential, Prevalence

\section{INTRODUCTION}

Toxoplasmosis is a major parasitic zoonotic disease of almost all warm blooded animals including human beings. This disease is caused by an obligate intracellular protozoan parasite Toxoplasma gondii. T. gondii affects over 350 species of vertebrates. Based on serological investigations, it is estimated that one third of the world's human population has been exposed to this widespread zoonotic agent (Innes 2010; Pereira et al., 2010; Montoya and Liesenfeld, 2012). In Bangladesh, seroprevalence of toxoplasmosis in human was 38.5\% (Ashrafunness et.al., 1998), $12.4 \%$ in blood donors, $11.8 \%$ in pregnant women, $50 \%$ in butchers (Samad et.al., 1997) 
and $15.89 \%$ in women (Samad et.al., 1993). T. gondii is recognized as an important opportunistic pathogen of fetuses, newborns and patients with a variety of primary and secondary immunodeficiency (Petersen et.al., 2001). In Mymensingh district, seroprevalence for toxoplasmosis were also recorded in cattle-12\%, sheep- $40 \%$ and goats-32\% (Shahiduzzamanet al., 2011) and cattle-16.10\%, sheep-17.65\% and goats-12.09\% (Samad et al., 1993).

The ingestion of tissue cysts from undercooked meat and consuming food as well as water contaminated with oocysts are the two most important modes of transmission of $T$. gondii in humans. Felids play a pivotal role for $T$. gondii as definitive hosts, because they excrete environmentally resistant oocysts in faeces and contaminate soil, food and water.

Cats are the most popular pet in the world, and are now found in almost every place where humans live (Driscoll et.al., 2009). No doubt Bangladesh has unknown number of domestic, stray and wild cats. One report showed 33.33\% seropositive of $T$. gondii in cats in Bangladesh (Samad et.al., 1997). Usually cats do not show the clinical signs even during shedding of oocysts. It means subclinical form occurs in cat. So cats have a key and crucial role in the epidemiology of toxoplasmosis, so expanding the basic knowledge about $T$. gondii infection in cats is a matter of importance. A little is known of toxoplasmosis in cats in Bangladesh and there is no information on the excretion of $T$. gondii oocysts by cats in Bangladesh. Therefore, here we emphasize to report the presence of $T$. gondii oocysts in cat faeces and contaminated water for the first time in Bangladesh.

\section{MATERIALS AND METHODS}

\section{Examination of cat feces for $T$. gondii oocysts}

Altogether 254 samples of cat feces were collected from Mymensingh (in and around BAU campus) in the period from September 2014 to August 2016. People having cats were requested to collect cat faeces in plastic bag and were dispatched to Department of Parasitology, BAU. Faeces were collected cats from student residential place and staff quarters areas of BAU. The cat feces were examined for the presence of $T$. gondii oocysts using Sheather's sugar flotation as was previously described by Dubey and Beattie (1988); Barutzki and Schaper (2003); Dubey et. al., (2006); Schares et.al., (2008); Dubey JP (2009). Briefly, feces (2-10 gm) of each cat was floated in sucrose solution (454 gm sugar, $355 \mathrm{ml}$ water and $6 \mathrm{ml}$ formalin; specific gravity, 1.203), filtered through gauze and centrifuged in a $15 \mathrm{ml}$ tube at $1500 \mathrm{rpm}$ for $10 \mathrm{~min}$. A drop of the float from the meniscus was examined microscopically between cover slip and glass slide at 200X magnification. Oocyst was subspherical to spherical in shape, 10-12 $\mu \mathrm{m}$ in diameter in size, thick walled structure, containing cellular structures, as there is no maturation to sporozoites at this stage. Measurements of oocysts were taken with the aid of an ocular micrometer.

\section{Examination of Water Samples for T. gondii Oocysts}

A total of 390 water samples were collected from different water sources (tap/tube well, pond, drain, stagnant water) at Bangladesh Agricultural University (BAU) campus and adjacent villages like Sheshmore, Sutiakhali, Digerkanda, Fakirkanda, Bhagnabari, Chaurkalibari and 
Kewatkhali of Mymensingh from September 2014 to August 2016. Sample size was estimated by using the following formula according to Thrusfield (2007):

where $\mathrm{n}$ is required sample size; 1.96 is the $\mathrm{z}$ value for $95 \%$ confidence interval; The $\mathrm{P}_{\exp }$ (expected prevalence) of water samples is assumed 50\% if prevalence is unknown; $\mathrm{d}$ is desired absolute precision $=5 \%$.

Samples after pre-filtration step were brought to the Department of Parasitology, BAU for further processing and examination. Water samples were examined for the presence of T. gondii oocysts as described by Kourenti et.al. (2003). Briefly, about 30-50 litres each water samples were collected and were filtered with successive decreasing mesh sieves (pre-filtration step) could be incorporated to remove large particles. Then filtration was again performed with one micron pore size polyester filter bag (Duda). The filtrate was washed with $0.5 \%$ Tween-20 (laureth-12, polyoxy-ethylensorbitan-monooleate) into $15 \mathrm{ml}$ testtube (Figure 1. a, b, c, d). The oocysts were floated with sucrose solution (specific gravity: 1.203) by centrifuging at $1500 \mathrm{rpm}$ for $10 \mathrm{~min}$. A drop of the float from meniscus was placed on a clean glass slide, was covered with coverslip and was examined for oocysts microscopically.
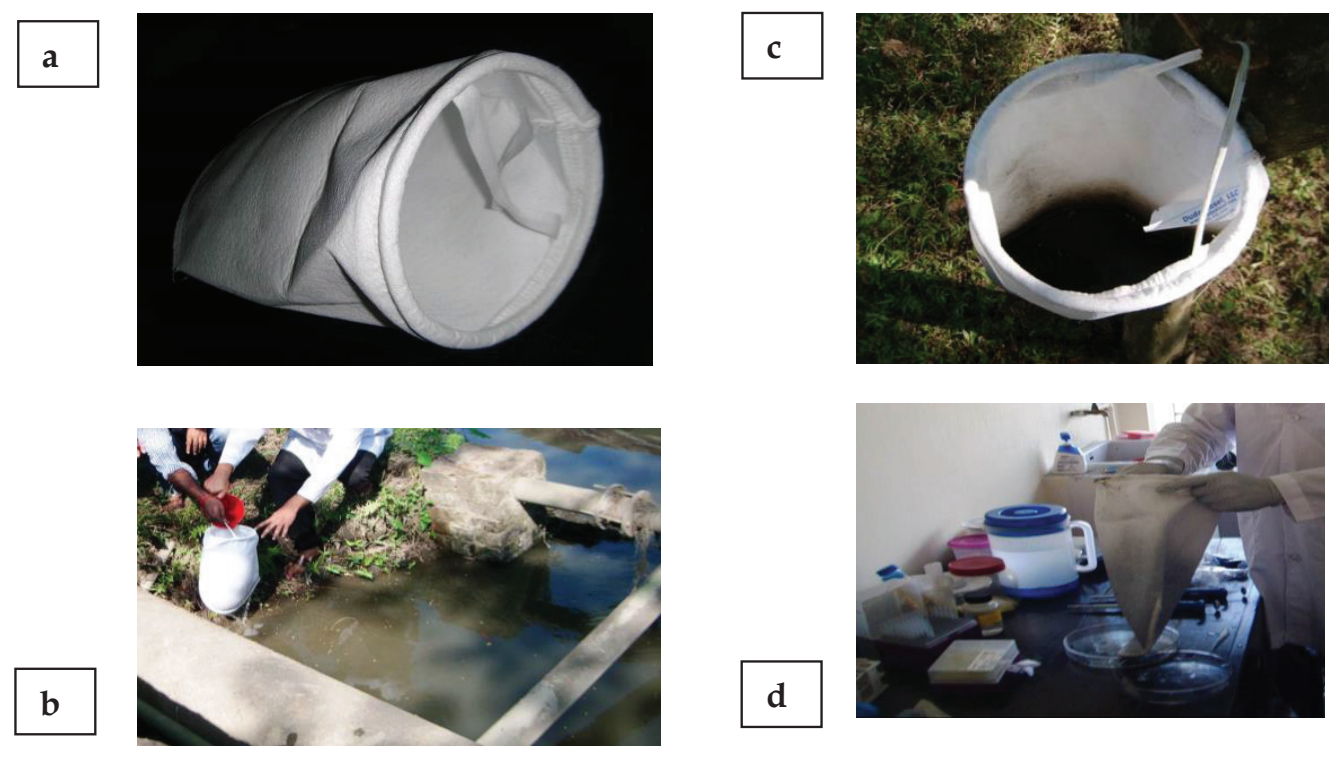

Figure1. Collection and processing of water samples. a) One micron polyester filter bag (Duda), b) Collection of water sample from waste water body, c) Filtration of water sample by filter bag, d) Collection of concentrated sample in filter bag with dispersion detergent Tween-20

Analysis: In this study domestic environmental conditions of thecats were defined as: household cats (indoor only) and street cats (both indoor and outdoor). Age of cat was categorized as young ( $<4$ months) and adult ( $\geq 4$ months). Season was divided into three: Summer (Mar-Jun), Rainy (Jul-Oct) andWinter (Nov-Feb). Obtained data were compiled in Microsoft Excel and analyzed. 


\section{RESULT}

Study was being performed for two years. After examining the samples (cat faeces- 254 and water samples- 390), the overall presence of T. gondii oocysts was found 4.03\% (26/644).

\section{Detection of $\boldsymbol{T}$. gondii oocysts in faecal samples}

A total of 254 cat faeces were examined and the prevalence of $T$. gondii oocysts was $5.5 \%$ in cat faeces (Table 1, Figure 2).

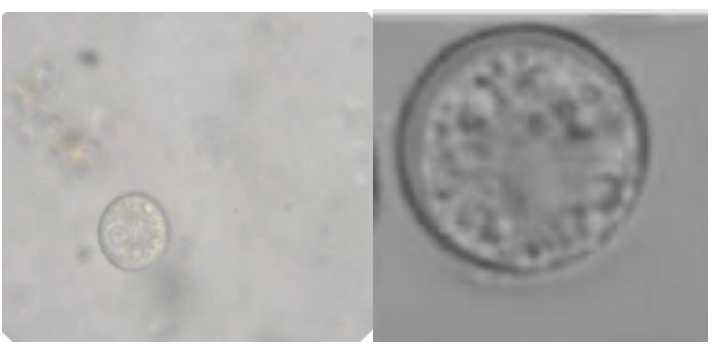

Figure 2. T. gondii oocyst (40X; right one magnified)

Table 1. Distribution of $T$. gondii oocysts in fecal samples based on age of cat and season

\begin{tabular}{|l|c|c|c|}
\hline Category & No of sample & Positive for oocyst & Percentage (\%) \\
\hline Overall & 254 & 14 & 5.5 \\
\hline Age & 150 & 10 & 6.7 \\
\hline Adult cat & 104 & 4 & 3.8 \\
\hline Young cat & 134 & 9 & 6.7 \\
\hline Season & 50 & 2 & 4.0 \\
\hline Summer (Mar-Jun) & 70 & 3 & 4.3 \\
\hline Rainy (Jul-Oct) & & & \\
\hline Winter (Nov-Feb) &
\end{tabular}

\section{Detection of $T$. gondii Oocysts in Environmental Samples}

The prevalence of $T$. gondii oocysts was 3.08\% (12/390) in water samples as shown in Table 2. 
Table 2. Distribution of $T$. gondii oocysts and other oocysts in water sample based on different water sources and seasons

\begin{tabular}{|l|c|c|c|c|}
\hline Category & $\begin{array}{c}\text { No of } \\
\text { sample }\end{array}$ & $\begin{array}{c}\text { Positive for } T . \\
\text { gondii oocyst }\end{array}$ & $\begin{array}{c}\text { Prevalence } \\
\%\end{array}$ & $\begin{array}{c}\text { Positive for oocysts } \\
\text { other than T. gondii }\end{array}$ \\
\hline Overall & 390 & 12 & 3.08 & $66(16.92 \%)$ \\
\hline Water sources & 120 & 0 & 0 & $0(0 \%)$ \\
\hline Tap water/tube well & 90 & 3 & 3.33 & $15(16.67 \%)$ \\
\hline Pond & 90 & 6 & 6.67 & $34(37.78 \%)$ \\
\hline Drain & 90 & 3 & 3.33 & $17(18.89 \%)$ \\
\hline Stagnant water in field & \multicolumn{5}{|l}{} \\
\hline Season & 130 & 3 & 2.31 & \\
\hline Summer (Mar-Jun) & 150 & 6 & 4.0 & \\
\hline Rainy (Jul-Oct) & 110 & 3 & 2.73 & \\
\hline Winter (Nov-Feb) &
\end{tabular}

Except tap/tubewell, all three water sources were found to be contaminated with T. gondii oocysts. Drain water was found highly contaminated in this study.In addition to take water samples, the presence of cats in those areas and their activities were observed in this study (Figure 3).

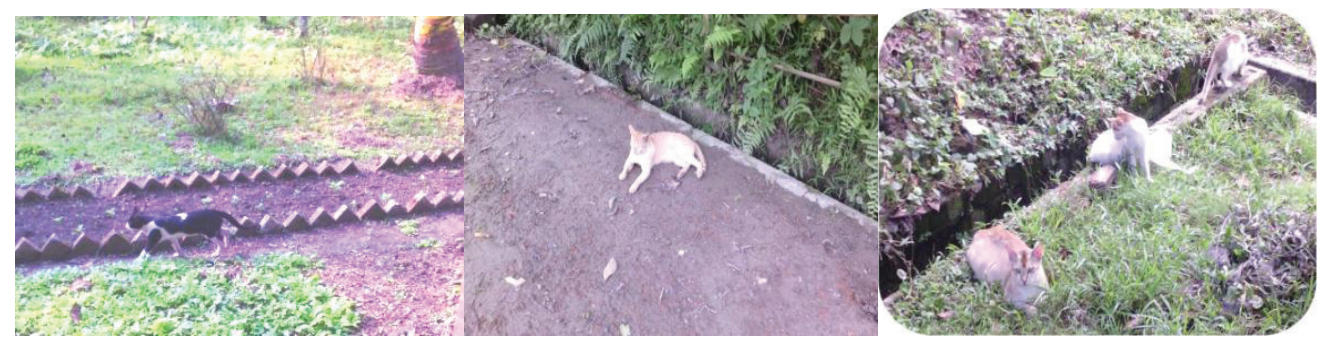

Figure 3. Cats wandering and contaminating environment at BAU area

All of the noticed cats were free roaming but with limited access to households and none had specific owner. It was also noticed that people offered left over feed to cats. Additionally, it was found that cats were living in close contact with human dwellers and animal houses.

\section{DISCUSSION}

\section{Detection of $T$. gondii oocysts in Faecal Samples}

The finding of this study was very high from reports of other authors (Dabritz et.al., 2007; Bizhga B, 2017). In Bangladesh, there are limited organized animal farms and cats are wandering everywhere in studied areas contaminating the grass or pasture. So, cattle, sheep and goats are usually kept in pasture for grazing, and therefore they have an increased risk of infection due to contamination of the environment with sporulated oocysts shedded by cats.

Hence, people may get infection after eating undercooked meat of these animals which is rare due to food habit of Bangladeshi people. People can also get infection by eating unwashed 
vegetables, fruits due to contamination of the environment or kitchen garden with sporulated oocysts. People can get accidental infection when they are working in garden and field etc.

Summer season (March to June) showed higher prevalence. In fact, soil contamination by $T$. gondii oocysts is not a stationary event because it can vary depending on the presence of feline excretion of oocysts in faeces and on environmental conditions such as temperature and moisture (Dubey 2004; Casartelli-Alves et.al., 2015). Several studies have confirmed a link between toxoplasmosis outbreaks and water contamination with oocysts (Cook et.al., 2000; Dubey, 2004). After contamination of soil with oocysts, oocysts may reach into water source by wind; rain etc. and then water become contaminated.

Adult cats were affected more than young $(<4$ months old) by this protozoa. It is expected that with increasing age, exposure of cats to T. gondii infection also increases (Miro et.al., 2004; Alvarado et.al., 2012). This may be due to feeding cats with raw meat and infrequent cleaning of the litter box (Besne et.al., 2008). Young cats might get infection via congenital transmission from infected dam or from milk.

All of the studied cats were free roaming but with limited access to households and none had specific owner. In general street cats are more prone to $T$. gondii infection compared to household cats because street cats could acquire the infection through catching the rodents, birds, reptiles and raw food scraps.

\section{Detection of $T$. gondii Oocysts in Eenvironmental Samples}

The prevalence of $T$. gondii oocysts was $3.08 \%$ in water samples in this study. Transmission of T. gondii via drinking water has been reported in the context of outbreaks and as a risk factor in toxoplasmosis-endemic areas (Jones and Dubey 2010, Karanis et.al., 2013, Krueger et.al., 2014). However, estimation of the levels of host exposure to T. gondii oocysts water is a complex and multifactorial subject.

Absence of T. gondii oocysts was found in tap/tubewell water sources. It is because of no chance for contamination of such water with oocysts. That is why such water sources can be assumed as Toxoplasma safe. Such water can be contaminated outside after taking out from tap/tubewell.

Among four water sources, drain water was found to be more contaminated with T. gondii oocysts. Drain water contains water from many places like kitchen, hotel, animal sheds, gardens etc and these places are liked by cats for food, shelter and play.

The study showed pond water can be contaminated with this protozoan. This might be due to washing of contaminated vegetables in pond water before taking to market (Bangladeshi trend) and cleaning kitchen utensils near the pond. During cleaning, few kitchen leftover materials like fish, fish spines, meat etc were left aside and these materials are good attraction for coming cats there and thereby pond water become contaminated after shedding oocysts.

The present study showed that stagnant water can be the source of infection. Lack of proper drainage facility enhances the water stagnant everywhere in the field. Generally, cats are wandering everywhere in the country and they are contaminating the environment with sporulated oocysts. Animals like cattle, sheep and goats are usually kept in pasture for grazing, and therefore they have an increased risk of infection due to drinking of contamination water. 
T. gondii oocysts were found higher in rainy season (July to October). In rainy season oocysts might come up from soil and grazing areas or pasture to the water sources due to flow of water and thereby make contamination to water sources.

\section{CONCLUSION}

There is presence of $T$. gondii oocysts in the environment (cat faeces, water), which might be hazardous for both public and animal health. Hence this disease has great zoonotic importance around BAU campus and therefore needs to develop public awareness.

\section{ACKNOWLEDGEMENT}

The authors are thankful to laboratory staffs of Department of Parasitology, BAU for laboratory support during experiment.

\section{REFERENCES}

Alvarado Esquivel, C., Garcia Machado, C., Alvarado Esquivel, D., Vitela Corrales, J., Villena, I. and Dubey, J.P. (2012). Seroprevalence of Toxoplasma gondii infection in domestic sheep in Durango State, Mexico. J Parasitol, 98: 271-3.

Ashrafunnessa, Khatun, S., Islam, M.N. and Huq, T. (1998). Seroprevalence of Toxoplasma Antibodies among the Antenatal Population in Bangladesh. J. Obstet. Gynaecol. Res, 24 (2): 115-119.

Barutzki, D.B. and Schaper, R. (2003).Endoparasites in dogs and cats in Germany 1999- 2002. Parasitology Research, 90: S148-S150.

Besne Merida, A., Figueroa Castillo, J.A., Martfnez Maya, J.J., Luna Pasten, H., Calderon Segura, E. and Correa, D. (2008). Prevalence of antibodies against Toxoplasma gondii in domestic cats from Mexico City. Vet Parasitol, 157: 310-3.

Bizhga, B. (2017). Toxoplasmosis under coproscopic diagnosis in cats. Albanian Journal of Agricultural Sciences, pp. 597-603.

Casartelli-Alves, L., Amendoeira, M.R.R., Boechat, V.C., Ferreira, L.C., Carreira, J.C.A., Nicolau, J.L., Trindade, E.P.F., Peixoto, J.N.B., Magalhães, M.A.F.M., de Oliveira, R.V.C., Schubach, T.M.P. and Menezes, R.C. (2015). Mapping of the environmental contamination of Toxoplasma gondii by georeferencing isolates from chickens in an endemic area in southeast Rio de Janeiro state, Brazil. Geospatial Health, 10: 311.

Cook, A.J.C., Gilbert, R.E., Buffolano, W., Zufferey, J., Petersen, E., Jenum, P.A., Foulon, W., Semprini, A.E. and Dunn, D.T. (2000). Sources of Toxoplasma infection in pregnant women: European multicentre case control study. Br Med J, 321: 142-147.

Dabritz, H.A., Miller, M.A., Atwill, E.R., Gardner, I.A., Leutenegger, C.M., Melli, A.C. and Conrad, P.A. (2007). Detection of Toxoplasma gondii-like oocysts in cat feces and estimates of the environmental oocyst burden. J Am Vet Med Assoc, 231 (11):1676-84.

Driscoll, Carlos A., Clutton-Brock, J., Kitchener Andrew, C. and O'Brien, S.J. (2009). "The Evolution of House Cats". Scientific American. New York: Nature Pubg. Group. Retrieved 26 August 2009.

Dubey, J.P. (2004). Toxoplasmosis- A waterborne zoonosis. Vet Parasitol, 126: 57-72.

Dubey, J.P. (2009).Toxoplasmosis of Animals and Humans. CRC Press Inc., Boca Raton, New York, pp. 1-313. 
Dubey, J.P. and Beattie, C.P. (1988).Toxoplasmosis of Animals and Man. CRC Press, Boca Raton, Florida, USA, pp. 1-220.

Dubey, J.P., Sub, C., Cortes, J.A., Sundar, N., Gomez-Marin, J.E., Polo, L.J., Zambrano, L., Mora, L.E., Lora, F., Jimenez, J., Kwok, O.C.H., Shen, S.K., Zhang, X., Nieto, A. andThulliez, P. (2006).Prevalence of Toxoplasma gondii in cats from Colombia, South America and genetic characterization of $T$. gondii isolates. Veterinary Parasitology, 141: 42-47.

Innes, E.A. (2010). A brief history and overview of Toxoplasma gondii. Zoonoses and Public Health, 57 (1): 1-7.

Jones, J.L. and Dubey, J.P. (2010). Waterborne toxoplasmosis - Recent developments. Experimental Parasitology, 124: 10-25.

Karanis, P., Aldeyarbi, H.M., Mirhasehemi, M.E. and Khalil, K.M. (2013). The impact of the waterborne transmission of Toxoplasma gondii and analysis efforts for water detection: an overview and update. Environmental Science and Pollution Research International 86-99.

Kourenti, C., Heckeroth, A., Tenter, A. and Karanis, P. (2003). Development and application of different methods for the detection for Toxoplasma gondii in water. Appl. Environ. Microbiol, 69: 102-106.

Krueger, W.S., Hilborn, E.D., Converse, R.R. and Wade, T.J. (2014). Drinking water source and human Toxoplasma gondii infection in the United States: a cross-sectional analysis of NHANES data. BMC Public Health, pp. 711.

Miro,G.,Montoya, A., Jimenez, S., Frisuelos, C., Mateo, M. and Fuentes, I. (2004). Prevalence of antibodies to Toxoplasma gondii and intestinal parasites in stray, farm and household cats in Spain. Veterinary Parasitology, 126: 249-255.

Montoya, J. and Liesenfeld O. (2012). Toxoplasmosis. Lancet, 363: 965-976.

Pereira, K.S., Franco, R.M. and Leal, D.A. (2010). Transmission of toxoplasmosis (gondii) by foods. Advances in Food and Nutrition Research, 60: 1-19.

Petersen, E. and Dubey, J.P. (2001). Biology of Toxoplasmsosis. In: Joynson DHM, Wreghitt TG, editors. Toxoplasmosis. Cambridge University Press, pp. 1-42.

Samad, M.A., Dey, B.C., Chowdhury, N.S., Akhtar, S. and Khan, M.R. (1997). Seroepidemiological studies on Toxoplasma gondii infection in man and animals in Bangladesh. Southeast Asian J. Trop. Med. Publ. Health, 28 (2): 339-343.

Samad, M.A., Begum, N., Shamsunahar and Ahmed, M.U. (1993). Serological diagnosis of Toxoplasma gondii infection in women associated with gyneco-obstetric problems. Southeast Asian J Trop Med Public Health, 24 (1): 102-6.

Schares, G., Vrhovec, M.G., Pantchev, N., Herrmann, D.C. andConraths, F.J. (2008). Occurrence of Toxoplasma gondii and Hammondiahammondioocysts in the faeces of cats from Germany and other European countries. Veterinary Parasitology, 152 (1-2): 34-45.

Shahiduzzaman, M., Islam, M.R., Khatun, M.M., Batanova, T.A., Kitoh, K. and Takashima, Y. (2011).Toxoplasma gondii seroprevalence in domestic animals and humans in Mymensingh District, Bangladesh. J. Vet. Med. Sci, 73 (10): 1375-1376.

Thrusfield M 2007: Veterinary Epidemiology. $3^{\text {rd }}$ edn. Blackwell Science Ltd, Oxford, UK, pp. 228-246. 